\title{
COINVESTIGAR A DISTÂNCIA EM TEMPOS DE CIBERCULTURA: RELATO DE UMA EXPERIÊNCIA SOBRE COEMPREENDER
}

\author{
Bento Duarte Silva* \\ Karine Pinheiro Souza**
}

\section{RESUMO}

No quadro de um projeto de investigação-ação sobre TIC e Empreendedorismo, este artigo apresenta o recorte da validação de conceitos sobre empreender em rede (coempreender). Este processo foi realizado na fase de reflexão, a qual, pelo fato dos diversos atores implicados se encontrarem em lugares diversos (Inglaterra, Portugal e Brasil), apenas podia ser conseguido recorrendo às tecnologias da comunicação ubíqua. Assim, neste artigo, efetuamos o relato dessa experiência de forma a averiguar até que ponto as tecnologias da comunicação ubíqua permitem e favorecem o processo de coinvestigação a distância. Com fundamento na teorização na Educação a Distância em tempos da Cibercultura e da construção do conhecimento nas redes educativas online, a metodologia de pesquisa aproximou-se da estratégia de um grupo focal online e da coinvestigação (OKADA, 2014). Os participantes constituíram uma comunidade de investigação, usando as tecnologias de comunicação assíncrona (fórum, 13 participantes) e síncrona (webconferência, 10 participantes) para consolidar as categorias do coempreender. No tratamento de dados recorremos à sociometria e à análise de conteúdo. Os resultados mostram que tecnologias da comunicação ubíqua revelaram-se à altura do objetivo pretendido, pois, apesar da distância e dos participantes se encontrarem em lugares diferentes, foi possível construir conhecimento sobre o tema.

Palavras-chave: Investigar a distância. Redes educativas online. Tecnologias de comunicação ubíqua. Coinvestigação. Coempreender.

\begin{abstract}
DISTANCE CO-RESEARCH IN THE ERA OF CYBERCULTURE: REPORT OF AN EXPERIENCE ABOUT CO-ENTREPRENEURSHIP

In the context of an action research project concerning ICT and Entrepreneurship, this paper presents validation of concepts regarding network entrepreneurship (Coentrepreneurship). This process took place in the reflection phase, which, because the participants involved were in distant locales (England, Portugal, and Brazil), could only be achieved using ubiquitous communication technologies. As such, this article relates this experience, in an attempt to determine the extent to which the ubiquitous communication technologies enable and support the distance co-research
\end{abstract}

\footnotetext{
* Professor Catedrático do Instituto de Educação da Universidade do Minho (Braga/Portugal). Doutorado em Ciências da Educação - Tecnologia Educativa. bento@ie.uminho.pt

** Doutora em Tecnologia Educativa pela Universidade do Minho. Professora Orientadora da Célula de Formação (SeducCE).kpinheiro.projetos@gmail.com
} 
process. Based on the theory of Distance Education in the era of Cyberculture and the construction of knowledge via online educational networks, the research methodology adopted a strategy involving an online focus group and co-research (OKADA, 2014). Participants formed an investigative community, using communication technologies that were both asynchronous (a forum of 13 participants) and synchronous (a web conference with 10 participants) to consolidate the co-entrepreneurship categories. The resulting data was processed using sociometric methods and content analysis. Findings show that ubiquitous communication technologies meet the desired goal; in spite of distance, and the fact that participants were in different locales, it was possible to create knowledge.

Keywords: Distance research. Online educational networks. Ubiquitous communication technologies. Co-research. Co-entrepreneurship.

\section{RESUMEN}

\section{CO-INVESTIGAR A DISTANCIA EN TIEMPOS DE CIBERCULTURA: RELATO DE UNA EXPERIENCIA SOBRE CO-EMPRENDER}

En el marco de un proyecto de investigación-acción sobre TIC y Emprendimiento, este artículo presenta el reporte de la validación de conceptos sobre emprender en red (Co-emprender). Este proceso fue realizado en la fase de reflexión, la cual, por el hecho de que los diversos actores implicados se encontraran en lugares diversos (Inglaterra, Portugal y Brasil), apenas podía ser logrado recurriendo a las tecnologías de la comunicación omnipresente. Así, en este artículo, se efectuó el relato de esa experiencia de tal forma que se pudiera averiguar hasta qué punto las tecnologías de la comunicación ubicua permiten y favorecen el proceso de co-investigación a distancia. Con fundamento en la teoría de la Educación a Distancia en tiempos de Cibercultura y de la construcción del conocimiento en las redes educativas online, la metodología de investigación se acercó a la estrategia de un grupo focal online y de la co-investigación (OKADA, 2014). Los participantes constituyeron una comunidad de investigación, usando las tecnologías de comunicación asíncronica (foro, 13 participantes) y síncrona (webconferencia, 10 participantes) para consolidar las categorías de co-emprender. En el tratamiento de datos se recurrió a la sociometría y al análisis de contenido. Los resultados muestran que las tecnologías de la comunicación ubicua se revelan a la altura del objetivo pretendido, pues, a pesar de la distancia y que los participantes se encuentran en lugares diferentes, fue posible construir conocimiento sobre el tema.

Palabras clave: Investigar a Distancia. Redes Educativas online. Tecnologías de Comunicación Ubicua. Co-investigación. Co-emprender.

\section{Introdução}

Vivendo em tempos da cibercultura, em que as tecnologias de conexão contínua potenciam uma comunicação móvel e ubíqua, este artigo reflete sobre as possibilidades dessas tecnologias para promoverem a investigação a distância. Os estudos sobre a Educação a Distância $(\mathrm{EaD})$ têm incidido, na maioria das vezes, em aspetos relacionados a metodologias de ensino e aprendizagem, modelos de concepção de cursos, recursos didáticos e avaliação, raramente abordam o tema da investigação a distância. Este é, justamente, o assunto deste texto, que consideramos relevante para a Educação a Distância, pois a construção e difusão do conhecimento são vitais para esta modalidade educacional, 
processos estes que têm base na investigação, como esclarecem bastantes estudos integrados nas obras Construção do conhecimento em organizações na perspectiva das redes sociais (SAMPAIO; SOUZA; SILVA, 2013) e Epistemologia, construção e difusão do conhecimento (GALEFFI; MODESTO; SOUZA, 2011), editadas pela Universidade do Estado da Bahia.

Este estudo faz parte de uma investigação mais ampla, realizada na modalidade de investigação-ação no âmbito de um projeto de doutoramento (SOUZA, 2014), que teve como objetivo geral inserir os eixos TIC e Empreendedorismo na formação dos jovens e averiguar as mudanças nas suas vidas. Para tal, o Projeto "Agentes Digitais" foi aplicado, numa primeira etapa (setembro 2011 a janeiro 2012), com jovens brasileiros (em Fortaleza) e numa segunda etapa (novembro 2013 a fevereiro 2014) com jovens portugueses (em Braga), seguindo as fases recomendadas quer para a metodologia de Investigação-Ação (Planejamento, Ação, Observação, Reflexão), quer para a metodologia da Pedagogia Empreendedora (Sonhar, Conceber, Desenvolver, Implementar, Avaliar).

$\mathrm{Na}$ fase final do projeto houve a intenção de realizar uma reflexão conjunta, com alunos, professores e especialistas, para validar os conceitos explorados na investigação em torno da importância de empreender em rede, de forma colaborativa, num novo olhar sobre a educação empreendedora que designamos de Coempreender. Colocamo-nos, assim, perante o desafio de juntar participantes que se encontravam em três países (Inglaterra, Portugal e Brasil), localizados em dois continentes (Europa e América do Sul). Tal era um desafio para a comunicação ubíqua, pelo compartilhamento dos conhecimentos e experiências de pessoas interessadas no tema mas que viviam em vários lugares, muito distantes fisicamente.

Apresentamos, aqui, o relato da experiência ocorrida nessa fase da investigação, com o objetivo de averiguar até que ponto as tecnologias das redes de comunicação ubíqua permitem e favorecem o processo de coinvestigar a distância. Para o efeito, os participantes formaram uma comunidade de investigação e as estratégias metodológicas aproximaram-se das do grupo focal online e da coinvestigação, a qual tem como ideia principal ser um processo colaborativo de levantar questões e discutir conhecimentos prévios, num processo de pesquisa com as pessoas no espaço digital aberto (OKADA, 2014).

Iniciamos o artigo pelo referencial teórico do tema, a Educação a Distância em tempos de Cibercultura, passando depois aos procedimentos metodológicos adotados na pesquisa, seus resultados e discussão.

\section{Educação a Distância em tempos de Cibercultura}

A caraterização da Educação a Distância ainda nos aparece, na literatura, referenciada ao processo de ensino-aprendizagem, mediado por tecnologias, onde professores e alunos estão separados espacial e temporalmente. Esta concepção faz jus às primeiras fases, próprias das tecnologias dos séculos XIX e XX, do uso da correspondência postal e mesmo da mídia de massa (rádio e televisão), em que a comunicação entre professores e alunos, e entre alunos, era inexistente. Havia, então, uma separação espacial e temporal na comunicação entre os atores educativos.

Sucede, porém, que na parte final do século XX houve uma mudança radical no cenário socioétnico da informação e comunicação. Desde meados da década de 1980 que se processavam profundas mudanças nas tecnologias da comunicação, consubstanciadas na passagem de um mundo de átomos (analógico) para um mundo de bits (digital) (NEGROPONTE, 1995). Estabeleceu-se uma aliança estratégica entre o audiovisual, a informática e as telecomunicações, anunciando a convergência tecnológica e a constituição de uma rede comunicativa universal, a Internet. Estava em curso o que se entende hoje ser uma verdadeira revolução tecnológica no domínio das tecnologias de informação e comunicação, de tal modo que a designação sociedade em rede passou a ser uma expressão de uso corrente para identificar o tempo civilizacional da era de informação (CASTELLS, 2002).

Passou, então, a emergir um novo espaço comunicacional criado pelas comunicações mediadas pelo computador, surgido pela "interconexão 
mundial de computadores" (LÉVY 2000, p. 17), designado de ciberespaço, um neologismo adotado da obra ficcional de William Gibson, publicada em 1984, intitulada Neuromante. ${ }^{1}$

Foi precisamente na perseguição do sonho de criar uma rede universal que Tim Berners-Lee, utilizando a tecnologia e a linguagem hipertextual, apresentou em 1989 a proposta de criação do sistema de informação World Wide Web (popularizado pelas expressões Web ou WWW), "designado originalmente como um mundo interativo de partilha de informação, através do qual as pessoas podiam comunicar com outras pessoas e com máquinas" (BERNERS-LEE, 1996, p. 01).

É nesse contexto sociotécnico que se manifesta o conceito de cibercultura, o qual designa "o conjunto das técnicas (materiais e intelectuais), as práticas, as atitudes, as maneiras de pensar e os valores que se desenvolvem conjuntamente com o crescimento do ciberespaço" (LÉVY, 2000, p. 17). Os princípios orientadores de um programa da cibercultura (a interligação, a criação de comunidades virtuais e a inteligência coletiva) fazem-na convergir naquilo que caracteriza a sociedade global na era da informação: a sociedade em rede. As investigações do sociólogo Manuel Castells esclarecem que a interação social online desempenha um papel cada vez mais importante na organização social, no seu conjunto, podendo "constituir comunidades, ou seja, comunidades virtuais, diferentes das comunidades físicas, mas não necessariamente menos intensas ou menos eficazes em unir e mobilizar" (CASTELLS, 2004, p. 161). Assim, a cibercultura opera na teia de ligações sociais, econômicas e humanas, dando origem a um indivíduo ligado a milhões de outros, comunicando com eles, simultaneamente acedendo e criando conhecimento; partilhando e recebendo conhecimento; interagindo com o outro para aprender, ensinar e relacionar-se. Nestas

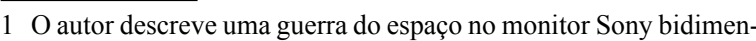
sional expressando-se da seguinte forma:

"O ciberespaço. Uma alucinação consensual, vivida diariamente por biliões de operadores legítimos, em todas as nações, por crianças a que se estão a ensinar conceitos matemáticos. Uma representação gráfica de dados abstraídos dos bancos de todos os computadores do sistema humano. Uma complexidade impensável. Linhas de luz alinhadas no não espaço da mente; nebulosas e constelações de dados. Como luzes de cidade, retrocedendo." (GIBSON, 2004, p. $65)$. possibilidades de intervenção, de modificação e de feedback residem as vantagens da cibercultura. Altera o modo de pensar e apreender o mundo, a visão de sociedade, da cidade e da cidadania (SILVA; PEREIRA, 2012).

A história da web tem apenas 25 anos de vida, mas a velocidade em que as transformações ocorrem já conhece três momentos, havendo autores que nos falam já do advento de uma Web 4.0. Se a primeira fase (Web 1.0) esteve muito focalizada em dispositivos da pesquisa de informação, a partir da virada do milênio foi desenvolvido um conjunto alargado de programas centrados na interatividade entre utilizadores que permitiram um maior relacionamento social, aspecto que levou a que Tim O'Reilly usasse, pela primeira vez, a expressão Web 2.0 (O'REILLY, 2005), também chamada de Web Social. De acordo com Spivack (2007), estamos neste momento (2010-2020) perante uma Web Semântica (Web 3.0), prevendo para a década de 2020-2030 o pleno desenvolvimento de uma web ubíqua (Web 4.0). Também Berners-Lee (2007), o criador da Web, prevê que o futuro passa pelo desenvolvimento de web ubíqua. Estas designações não são meras enumerações, pois traduzem, como bem esclarecem Halmann e Pretto (2011, p. 219), a propósito da emergência da web. 2.0, "epistemes emergentes na produção e difusão do conhecimento".

Com efeito, tem havido recentemente um notável desenvolvimento das tecnologias móveis (cujos maiores destaques recaem nas invenções em torno dos smartphones e dos tablets), a par das redes sem fios, proporcionando um reforço da conectividade, mobilidade e ubiquidade. Tais desenvolvimentos levaram a que a investigadora Lúcia Santaella adquirisse a "convicção de que a condição contemporânea da nossa existência é ubíqua" (SANTAELLA, 2013, p. 16). Para esta autora, mobilidade e ubiquidade estão associadas, pois são as tecnologias móveis que nos permitem estar em contato permanente (mesmo em deslocação) com uma pluralidade de lugares, em simultâneo. O desenvolvimento destas tecnologias, bem como um conjunto alargado de outras tecnologias com forte poder disruptivo (MANYKA et al., 2013), em que a designada "internet das coisas" é a face mais visível, levam a que alguns autores, como 
Kurzweill (2005), prevejam que uma nova singularidade tecnológica ${ }^{2}$ está próxima, com profundas repercussões na nossa forma atual de vida.

Quais as repercussões dessas inovações tecnológicas na $\mathrm{EaD}$ ? Como sabemos, cada tecnologia, em cada época histórica, teve um papel relevante na reordenação das relações do ser humano com o mundo e estimulou transformações noutros níveis do sistema sociocultural, incluindo o educacional (SILVA, 2008). Assim, há autores, como Gomes (2003, 2008), Garrison (1985) e Moore e Kearsley (2007), que colocam o fenômeno como uma evolução da EaD. Situando a $1^{a}$ geração em meados do século XIX com recurso ao serviço da correspondência postal, Maria João Gomes, em artigo de 2003, fala de uma $4^{a}$ geração que designa de "Aprendizagem em Rede", suportada nas tecnologias do correio eletrônico e conferências por computador (GOMES, 2003). Decorridos cinco anos, em artigo de 2008 já nos fala numa $6^{\text {a }}$ geração que designa de "mundos virtuais" suportada pelos "ambientes virtuais da web" (GOMES, 2008). Posição radicalmente diferente é apresentada por Silva (2003, 2009) e Santos (2014), pois, para estes autores, a cibercultura - "modos de vida e de comportamentos assimilados e transmitidos na vivência histórica e cotidiana marcada pelas tecnologias informáticas, mediando a comunicação e a informação via internet" (SILVA, 2009, p. 26) - traz um novo conceito, o da Educação Online, assumindo que esta "não é apenas uma evolução das gerações da EAD, mas um fenômeno da cibercultura" (SANTOS, 2014, p. 56), tanto mais que esta ganhou potência com as tecnologias da mobilidade e ubiquidade. Assim, para esses autores, a educação a distância é caraterizada ainda pela "separação física entre sujeitos aprendentes e/ ou formadores e seus dispositivos e narrativas de formação" (SANTOS, 2014, p. 55). Já no caso da educação online,

[...] os sujeitos podem até encontrar-se geograficamente dispersos, entretanto, em potência estão juntos e próximos, compartilhando informações, conhecimentos, seus dispositivos e narrativas de formação a partir da mediação tecnológica das e

2 Denominação dada a "um período futuro, durante o qual o ritmo da mudança tecnológica será tão rápido, e o seu impacto tão profundo, que a vida humana será transformada irreversivelmente" (KURZWEIL, 2005, p. 24). com as interfaces e dispositivos de comunicação síncronas e assíncronas e de conteúdos hipertextuais disponíveis no ciberespaço a partir do AVA. (SANTOS, 2014, p. 55-56).

Entendemos que vivemos, claramente, num tempo cibercultural dos espaços híbridos na educação, com grandes mudanças nas noções tradicionais de "espaço-tempo" da aprendizagem. A autora Maria Graça da Silva evidencia bem esse aspecto ao clarificar que

[...] a mobilidade na educação diminui e torna fluídas as fronteiras de comunicação entre escola, residência e trabalho, uma interferindo, influenciando e se imbricando na outra. Portanto, além do tempo e do espaço, o contexto da comunicação é ressignificado: a escola entra em casa e a casa entra na escola, bem como os amigos, a família, a comunidade... os espaços e os territórios informacionais são ampliados. (SILVA, M ${ }^{\mathrm{a}}, 2013$, p. 130).

Face a essa diluição das fronteiras comunicacionais, em que as interações presenciais e virtuais se complementam, entendemos que dentro de pouco tempo não fará mais sentido estabelecer diferenças entre educação presencial e educação a distância. Assim, no contexto de uma ecologia da comunicação em que o uso das tecnologias digitais converteu-se em algo cotidiano, ampliando as reflexões de Keegan (2002) em torno do e-learning, ${ }^{3}$ parece-nos adequado constatar que a modalidade (b-learning) ${ }^{4}$ está a conjugar as modalidades de ensino presencial (p-learning) e de ensino a distância (d-learning), e que o futuro, perante o desenvolvimento do m-learning (mobile learning), ao libertar os utilizadores das ligações fixas, permite-nos perspectivar uma evolução para uma maior conectividade e ubiquidade (c-learning e $u$-learning) nas comunidades de aprendizagem, características que marcarão os cenários educativos de inovação na sociedade digital (SILVA, 2014).

3 Este " $e$ ", inicial da palavra electronic, passou a ser utilizado em várias atividades da sociedade, remetendo para o uso de tecnologias digitais. No caso da educação, a designação adotada foi $e$-learning, um anglicismo que, face à dificuldade de tradução ("aprendizagem eletrônica"?), passou a ser comum utilizar-se.

4 Este " $b$ ", inicial da palavra blended, significa algo misto, combinado, passando a expressão $b$-learning a usar-se para caracterizar situações mistas, em que há uma complementaridade entre o presencial e o online. Face à evolução das tecnologias de comunicação síncrona, o presencial não remete apenas para uma presença física, mas sim um "estar juntos e próximos" no virtual. 
Temos realizado experiências educativas, quer no âmbito do b-learning, quer no do $u$-learning, cujos resultados de avaliação, particularmente junto dos alunos, revelam alta receptividade a estas modalidades (SILVA; CONCEIÇÃO, 2013; SILVA; FALAVIGNA, 2014).

Figura 1 - Do P-learning ao U-learning

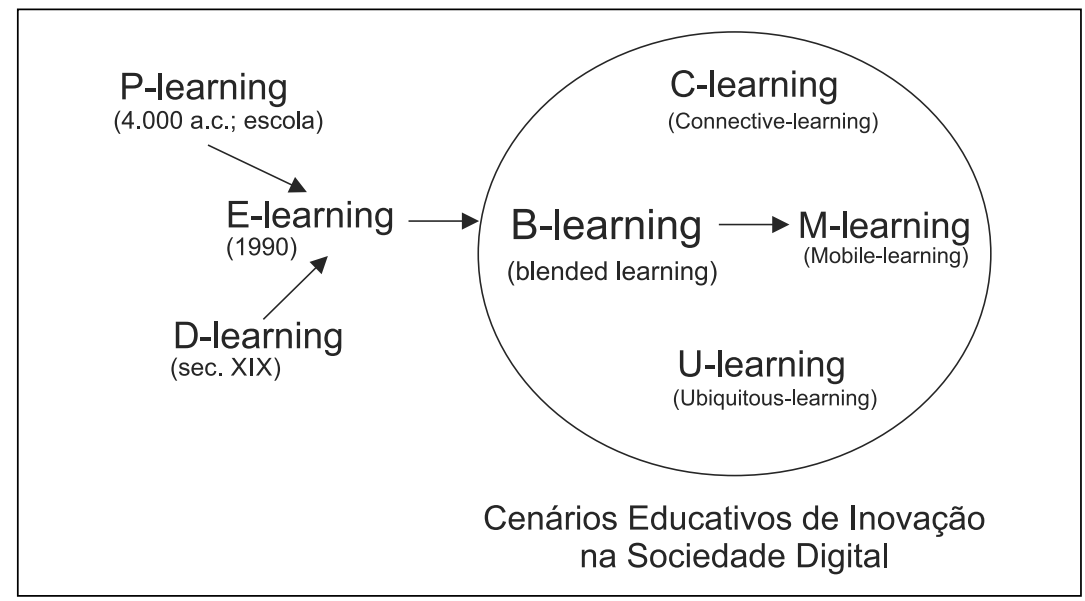

Fonte: Silva (2014, p. 43).

Este artigo situa-se, também, no terreno emergente das tecnologias de comunicação ubíqua, sendo o nosso contributo, como professores e investigadores em educação, aprender a investigar num mundo impregnado pelas tecnologias de conexão contínua. Como já descrevemos na introdução, na fase final do projeto pretendíamos validar conceitos sobre a temática em pesquisa (coempreender), mas como os diversos sujeitos implicados se encontravam em lugares distintos (Inglaterra, Portugal e Brasil), este objetivo apenas podia ser conseguido recorrendo às tecnologias da comunicação ubíqua. Assim, o relato dessa experiência, que a seguir apresentamos, destina-se a averiguar até que ponto as tecnologias da comunicação ubíqua permitem e favorecem o processo de coinvestigação a distância.

\section{Procedimentos metodológicos}

Para a fase de reflexão da metodologia de investigação-ação, pretendeu-se constituir uma comunidade de investigação, tomando o sentido interpretativo que Wenger, McDermott e Snyder $(2002$, p. 4) atribuem às comunidades de prática: "[...] grupos de pessoas que partilham uma preocupação, um conjunto de problemas ou o interesse por um tópico e que aprofundam o seu conhecimento e competência interagindo de forma contínua", pois estavam reunidas as três principais dimensões estruturais: o domínio, a comunidade e a prática. $\mathrm{O}$ domínio era a educação empreendedora, tendo como tema a importância do empreender em rede, de forma colaborativa, processo que deu origem ao conceito, que já tínhamos em mente, de Coempreender.

Desse modo, a intenção metodológica era a construção do conhecimento pelo compartilhamento de saberes (SAMPAIO; SILVA, 2013), através da "interação circular entre os conhecimentos tácitos e explícitos” (SOUZA; BURNHAM, 2011, p. 269). O conhecimento tácito refere-se, essencialmente, ao adquirido nas experiências vividas durante a formação na realização dos projetos; já o conhecimento explícito traduziu-se na revisão de vasta literatura sobre a sociedade em rede (CASTELLS, 2002, 2004), inteligência coletiva e cibercultura (LÉVY, 1998, 2000), múltiplos letramentos, com ênfase nas práticas sociais (SELBER, 2004), na educação para o empreendedorismo visitando um conjunto alargado de autores como Fillion e Dolabela (2007), Fayolle (2007), Senges, Brown e Rheingold (2008), Lopes (2010), Sarkar (2014), Kuratko (2013). Decorrendo a experiência em redes online, também houve mobilizações de saber sobre teorias da construção do conhecimento na web (HALMANN; PRETTO, 2011), sendo também 
enfatizada a teoria do ator-rede (Actor-Network Theory - ANT), proposta por Law (1992) e Latour (2000), pela observação da dinâmica da rede e a forma como os recursos foram utilizados para que a rede crescesse no compartilhamento de saberes.

Pela experiência que tínhamos da participação em comunidades de prática online, entendemos que seria apropriado beneficiar-se das vantagens de uso de interfaces de comunicação assíncrona e síncrona, pois estes espaços têm diferentes objetivos e proporcionam modos diversos de interação (SILVA; PEREIRA, 2012). O fórum, exemplo de interface de comunicação assíncrona, apresenta a vantagem de permitir intervenções mais refletidas, teoricamente suportadas, visto que proporciona maior liberdade temporal e é adequado à gestão individual da participação. Por sua vez, as interfaces de comunicação síncrona (de que a webconferência é o exemplo mais completo, pois permite interagir com a imagem e a voz dos participantes, a par do texto e outros dados) são facilitadores de brainstorming pelo imediatismo de opiniões e conexão entre temas, para além de possibilitar uma maior proximidade entre os participantes, fortalecendo o sentido de comunidade.

Entendemos, assim, realizar, num primeiro momento, um Fórum de Debate, prevendo um tempo de duração de cerca de 2 meses (fevereiro e março de 2014), finalizando, num segundo momento, com uma Webconferência síncrona, realizada no dia 22 de março (um sábado), em comum acordo entre os participantes, com a duração de 2 horas. Houve o cuidado prévio de assegurar o melhor dia da semana para disponibilidade síncrona e uma hora que atendesse à diferença horária entre os países: em Portugal e Inglaterra decorreu entre as 14 e 16 horas, que correspondia, no Brasil, ao período entre 10 e 12 horas.

A plataforma online utilizada para o Fórum foi o WESPOT (Working Environment with Social and Personal Open Tools for inquiry based learning), visto tratar-se de um "ambiente de trabalho para coaprendizagem baseada em coinvestigação com tecnologias sociais, personalizadas, analíticas, colaborativas e móveis" (OKADA, 2014, p. 36). Para a webconferência utilizamos o ambiente Flash Meeting, também com garantia de confiabilidade e de fácil apropriação das funcionalidades de acesso e uso.
O processo para a participação no Fórum iniciou-se com um convite encaminhado por e-mail, em finais de janeiro de 2014, aos alunos, professores e especialistas envolvidos no Projeto "Agentes Digitais", para que se tornassem "coinvestigadores", a fim de debater e validar os conceitos da educação para o empreendedorismo, mais especificamente da importância do empreender em rede. Seguimos as regras éticas da investigação sobre o conhecimento informado, sendo a adesão livre e voluntária. Responderem favoravelmente 13 participantes, das três qualidades: alunos, professores e especialistas.

Para o segundo momento (webconferência) manifestaram disponibilidade em participar 10 participantes do fórum, tendo também sido convidados a participar 3 pesquisadores, de três universidades do Brasil: 1 da Universidade Estadual do Ceará (UECE); 1 da Pontifícia Universidade Católica de São Paulo (PUC/SP); e 1 da Universidade Estadual do Rio Grande do Sul (UERGS). São professores universitários com conhecimento e experiência na compreensão da educação para empreendedorismo como um campo da ciência e com um vasto conhecimento sobre a relevância da rede para a educação no século XXI.

$\mathrm{O}$ número de participantes teve o quantitativo apropriado para planejarmos estes momentos com uma estratégia próxima à de grupo focal online, por atender às orientações desta técnica qualitativa e envolver atores de diversas áreas para refletir uma problemática de interesse comum (ABREU; BALDANZA; GONDIM, 2009).

Pretendíamos, também, que na comunicação interpessoal não se sentisse a relação dicotômica ou mesmo complementar "aluno versus professor versus especialista", devendo estes atuar numa relação de simetria, baseada na igualdade, para debater um assunto que era de conhecimento comum. Assim, atendemos ao princípio da permuta comunicacional simétrica, segundo a qual os participantes devem possuir oportunidades iguais para iniciar e sustentar a comunicação (WATZLAWICK; BEAVIN; JACKSON, 1973). Por isso, todos os participantes foram designados como "coaprendizages" e "coinvestigadores". Também a teoria Ator-Rede valoriza este princípio da simetria, indo até mais longe ao estabelecer uma simetria generalizada, pois a análi- 
se dos sujeitos e dos objetos deve ser feita sem que haja distinção entre eles, isto é, os fatores humanos e não humanos devem ser tratados na mesma ordem de importância (DEPONTI, 2008).

Para o tratamento dos dados, no que diz respeito à análise das dinâmicas comunicacionais, recorremos à sociometria, utilizando para o efeito o programa informático Ucinet, por ser adequado para elaborar a respectiva matriz das interações sociais. Para a análise dos movimentos comunicacionais, recorremos às categorias propostas por Silva e Ferreira (2009), que distinguem entre dois movimentos iniciadores (STR - Estruturação, que organiza o contexto para a atuação subsequente; e SOL - Solicitação, que se destina a provocar uma reação verbal ou física); e dois movimentos reflexivos (RES - Resposta, que tem uma relação recíproca com o movimento de solicitação; e REA - Reação, que tem o objetivo de avaliar, esclarecer, exemplificar ou modificar o que foi dito).

Para as categorias emergentes sobre o Coempreender, recorremos à técnica da análise de conteúdo, a qual vai além da mera análise descritiva do corpus, pois pretende chegar a uma análise de "significados" e "significantes" (BARDIN, 2014) pela interação com o discurso dos sujeitos da pesquisa, para compreender as suas representações e associação de ideias, no caso sobre a educação empreendedora com TIC. Esta análise foi desenvolvida com o apoio do software NVivo, tendo-se também utilizado o software tagul, programa específico para a criação da "nuvem de palavras" por possibilitar a criação de designs atrativos, em particular o que tem a forma de um "C", por estar em consonância com o conceito do Coempreender.

Foi efetuada uma validação da codificação com outros três investigadores, obtendo-se uma taxa de concordância de 87,5\% (nos movimentos de comunicação) e de $86,7 \%$ (nas categorias emergentes sobre o Coempreender), valores que apontam para uma validade significativa (FOX, 1981).

\section{Resultados e Discussão}

Os resultados apresentados dizem respeito às dinâmicas do processo de comunicação, fundamentadas com excertos da análise de conteúdo.
A questão inicial do fórum, norteadora de todo o debate - "Por que é importante empreender em Rede colaborativamente?" -, gerou 49 postagens, com um número total de 9.189 palavras, o que corresponde a 187,5 palavras por post. O comentário mais curto teve 24 palavras, e o mais longo 959. Por meio destas postagens, os participantes relataram as suas experiências, comentaram as competências desenvolvidas pelos jovens com o Projeto "Agentes Digitais" e refletiram teoricamente sobre a importância da colaboração no desenvolvimento dos projetos, validando o conceito de coempreender.

É de referir que, além das postagens em texto (escrito), houve recursos a outros textos com linguagem diversa, como vídeos, mapas conceituais, links, ligações a sites externos de projetos e experiências de educação empreendedora com TIC. Esta inter-relação de vários textos introduziu os participantes numa narrativa hipertextual, mais apropriada à lógica comunicacional da cibercultura.

A matriz sociométrica, apresentada na Figura 2, dá conta da riqueza das interações existentes. Não obstante existir um núcleo central mais ativo no processo de comunicação (constituído por 6 coaprendizes, nomeadamente o Coap 1, que moderou o debate e estabeleceu interações recíprocas com todos, seguido dos coaprendizes 5, 6, 9, 3 e 12), todos estabeleceram interação com todos, pois não existem nós soltos. Estivemos, assim, perante uma rede completa, com comunicação na modalidade todos-todos, que favoreceu a cocriação da comunicação, da coaprendizagem e da coinvestigação. É de referir, ainda, que os atores periféricos que estão na "borda da nuvem", usando a terminologia da metáfora proposta por Halmann e Pretto (2011, p. 231) ao fazerem uma analogia entre as redes e as nuvens: "Pense a web como uma nuvem. Você é uma das moléculas que formam a borda", mantiveram, em determinados momentos, um papel importante para determinar a forma da rede, virando mesmo o centro do debate. Ou seja, a Figura 2 sintetiza a dinâmica das interações totais, mas a rede, ao longo dos dois meses de duração do fórum, assumiu outras formas, foi uma rede mutante, os próprios atores que ocupam o centro foram rodando, houve centros móveis, deslocando-se à medida que os coinvestigadores intervinham no debate e provocavam impacto na discussão. 
Figura 2 - Matriz de interações do fórum WeSPOT

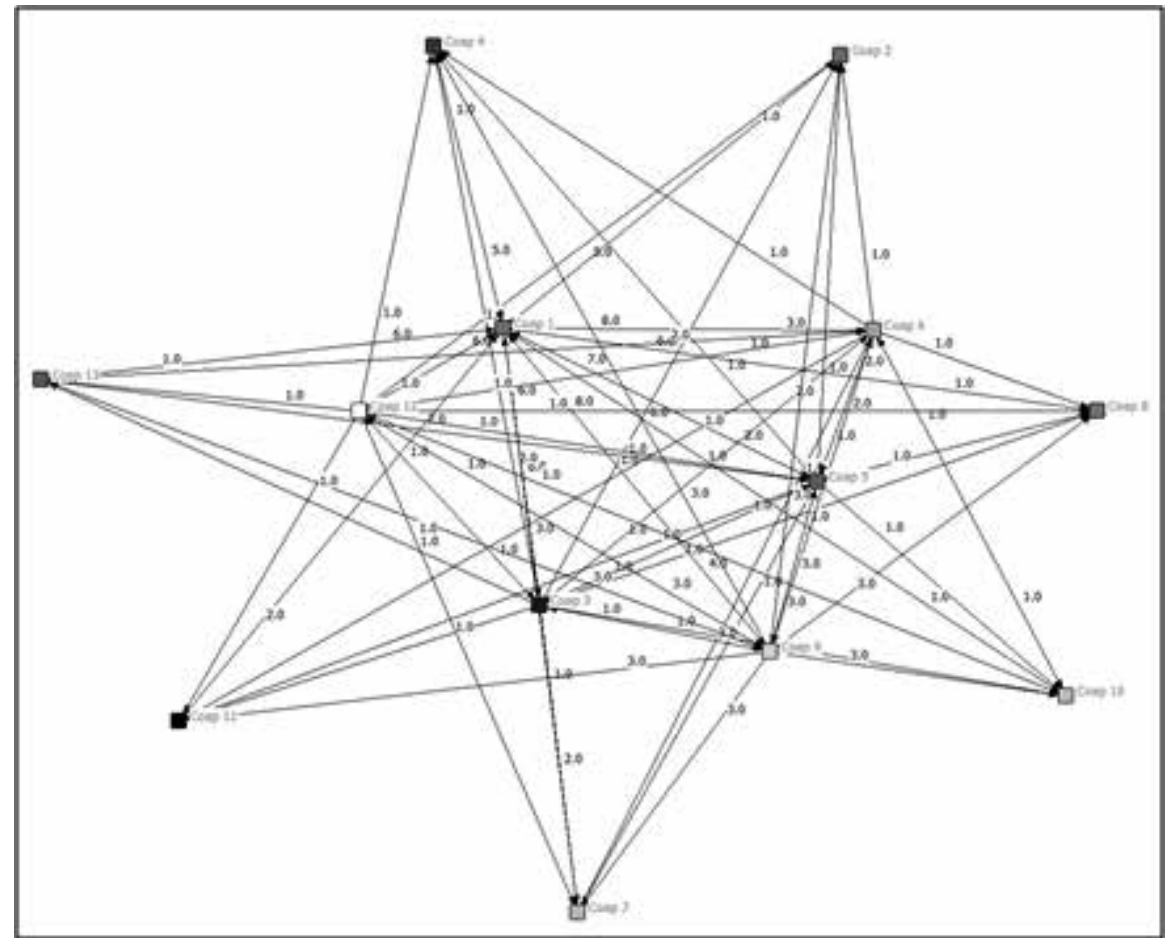

Fonte: Elaborado pelos autores deste artigo.

Essa intensidade do processo comunicacional refletiu-se na qualidade do debate e discussão temática, como podemos verificar pela análise dos movimentos comunicacionais. A codificação efetuada mostrou que estiveram em evidência os movimentos de Reação (25) e Resposta (23), em que os participantes avaliaram, modificaram e ampliaram os conceitos em debate (empreender em rede), apresentados no movimento de Estruturação (12), havendo também 16 movimentos de Solicitação (questões). Cabe relembrar que os movimentos de Estruturação e de Solicitação são iniciadores do ato comunicativo, ao passo que os movimentos de Resposta e de Reação são mais do tipo reflexivo. Os movimentos iniciadores foram, sobretudo, utilizados pela moderadora do fórum, mas também por outros atores mais ativos em termos de comentários.

O movimento de Estruturação (STR) destina-se a organizar o contexto para a atuação subsequente, como é exemplo o recorte seguinte: "Olá a todos e todas, gostaria de contribuir um pouco sobre o importante debate em redes de colaboração, sobretudo aquelas aplicadas ao empreendedorismo." (Coinvest9, STR).
O movimento de Solicitação (SOL), por norma, foi utilizado pela investigadora do projeto (moderadora do debate) para incentivar os alunos a relatarem os seus projetos, mas também por outros participantes de forma a solicitar uma melhor clarificação de aspetos relacionados ao desenvolvimento do projeto. Vejamos um exemplo:

Parabéns por esses projetos realizados pela Ação Agentes Digitais no Ceará, que resultaram em práticas de inclusão social: 100 jovens a gerar ideias e outros 200 a gerar negócios (48) em TIC, que maravilha! Será que alguns desses jovens podem relatar esse negócio, como o planearam e concretizaram? (Coinvest6, SOL).

O movimento de Resposta (RES) tem uma relação direta com o movimento de Solicitação. Majoritariamente foi realizado pelos alunos, mas também por outros participantes, principalmente a moderadora, que respondeu a todas as solicitações colocadas, quer a si, quer ao grupo. Vejamos um exemplo desse movimento:

Analisando a pergunta é preciso formular bem a resposta. Empreender se traduz como reinventar algo. Já existe a ferramenta, você apenas fará uma 
nova utilidade para a mesma. E empreender em rede, pode-se dizer que o conceito é basicamente esse, pois como estava afirmando, a rede (internet) já existe, por que não empreender utilizando a internet como ferramenta? (Coinvest7, RES).

Com o movimento de Reação (REA), os participantes avaliaram e ampliaram os assuntos e conceitos em debate. Foi o movimento mais utilizado, pela generalidade dos participantes, pois as respostas não se limitaram a meras palavras monossilábicas (do gênero "sim" ou "não"), mas a frases com um enunciado ampliado, com significado substantivo sobre o assunto. Vejamos dois exemplos, de dois participantes diferentes:

Parabéns pela autoavaliação da concepção do teu projeto, e destaco a aprendizagem das competências que referes: criatividade, espirito de equipa, capacidade de adaptação perante um ambiente desconhecido, melhorar o sentido de responsabilidade e autonomia. (Coinvest6, REA).

$\mathrm{O}$ tema do empreendedorismo diz-me muito, mas diz-me muito mais os aspectos relacionados com a educação empreendedora $\mathrm{e}$, consequentemente, a promoção da atitude empreendedora. Em todo este trabalho não devemos descurar de forma alguma a importância de todos os agentes educativos e agentes locais e nacionais responsáveis pelo desenvolvimento de uma cultura empreendedora. (Coinvest4, REA).

Como dissemos na metodologia, a esse momento assíncrono seguiu-se um outro momento síncrono, a webconferência. Curioso que esta vontade de estar juntos, ainda que no virtual, foi sentida numa postagem de um participante, sinal que tinha sido adquirido o sentimento de pertença a uma comunidade:

Quem sabe, não consigamos juntos nos convencermos (vencermos juntos) que o fenômeno da colaboração quando associada ao empreendedorismo seja um mecanismo importante para nossas novas demandas sociais, políticas, culturais ambientais e institucionais!? (Recorte do fórum WeSPOT Coinvest5).

A webconferência tinha o desafio adicional de colocar face-a-face 13 participantes, que viviam em 3 países localizados em 2 continentes, uma clara evidência da comunicação ubíqua: 2 participantes encontravam-se na Inglaterra (Milton Keynes), 3 em diferentes lugares de Portugal (Braga, Porto e
Penafiel) e 5 no Brasil, em diferentes lugares, bem distantes geograficamente: Fortaleza, São Paulo e São Francisco de Paula (Rio Grande do Sul). Estávamos perante o desafio de testar a potencialidade das atuais tecnologias digitais em propiciar uma comunicação ubíqua síncrona de qualidade.

$\mathrm{O}$ encontro iniciou-se com o lançar do desafio para partilhar palavras representativas do conceito do empreender em rede, e o debate foi crescendo, através da fala (e escrita) de cada participante, para se perceber o que se entendia sobre a importância das competências para empreender em rede.

Retomando a fala de Santaella (2013, p. 16) sobre o processo de comunicação ubíqua, quando diz que "em função da hipermobilidade, tornamo-nos seres ubíquos. Estamos, ao mesmo tempo, em algum lugar e fora dele", foi isso mesmo que sucedeu nessa sessão. Estando cada participante num lugar físico, estava também, em simultâneo, em outros lugares muito distantes geograficamente. Sendo um conceito que tem qualidades metafóricas (estar ao mesmo tempo em vários lugares), a ubiquidade é hoje uma questão, de fato, com raízes instauradas na computação das tecnologias de conexão contínua. Estas tecnologias tornam possível a realização de uma comunicação efetiva no ciberespaço, com repercussões na educação e na investigação, sobretudo se é perspectivado como “espaço do saber” (LÉVY, 1998).

A Figura 3 dá conta de algumas características da comunicação realizada, sendo interessante verificar que a sessão virtual adota vários sinais da linguagem usada na comunicação interpessoal face-a-face: enquanto na foto do lado esquerdo temos um território próprio do homo loquens - o local de realização dos conselhos comunitários primitivos $^{5}$-, na foto da direita temos um local desterritorializado do ciberespaço, apropriado para

5 A figura mostra a arquitetura de um edifício, a "Casa do Conselho", de um povoado fortificado (castro) da proto-história, a Citânia de Briteiros (próximo à cidade de Braga, Portugal), que data da Idade do Ferro (iniciada, na Península Ibérica, por volta de 500 anos a.C.). Era neste edifício que se reuniam os chefes das principais linhagens a fim de conversar sobre as colheitas, repartir tarefas comuns, sortear os baldios, debater e resolver conflitos, enfim, governar a comunidade. A forma da casa, em círculo, com bancos corridos em toda a extensão da parede interior, induz a possibilidade da existência de uma rede de comunicação completa, pois permite que todos interajam com todos, usando a plenitude dos signos da linguagem não verbal (cinésicos, proxémicos e paralinguísticos), a única existente na época (UNIVERSIDADE DO MINHO, 2015). 
realizar reuniões de grupo no séc. XXI. Embora as mídias utilizadas sejam radicalmente diferentes, permanecem, no entanto, alguns traços da marca genética da comunicação interpessoal, não somente pela manifestação da vontade de "estar juntos", mas também em aspectos de organização da reunião, tais como: nos cumprimentos/saudações no início e final, no cuidado da moderação das intervenções, nos tempos do uso da fala, no uso do ícone de levantar a mão para pedir permissão para falar ( $\mathrm{O}$ ) etc.

Figura 3 - Territórios da comunicação interpessoal: homo loquens versus homo digitalis

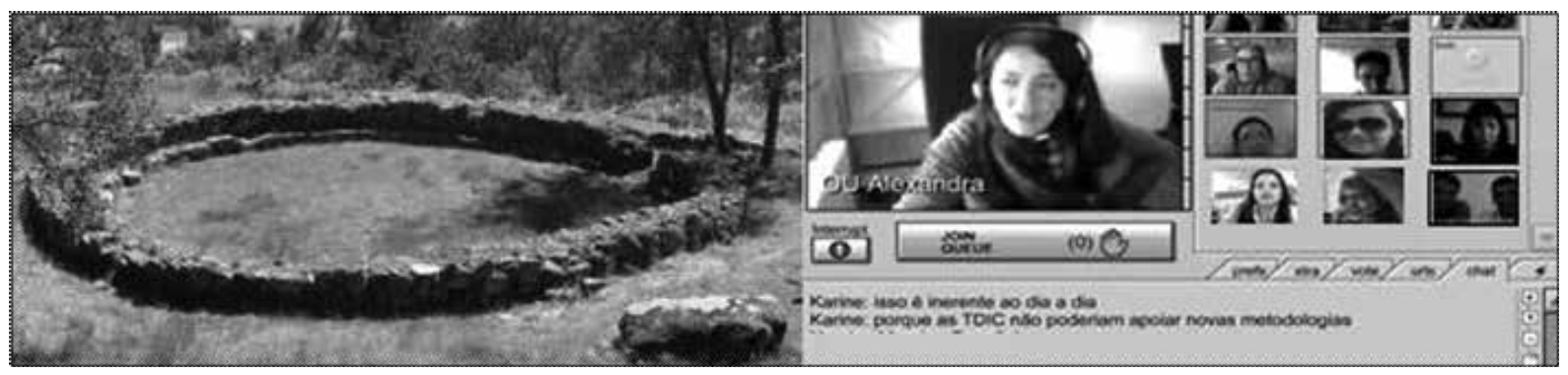

Fonte: Elaborado pelos autores deste artigo.

Sendo a comunicação marcada por processos virtuais realizados no ciberespaço, cabe relembrar o conceito de "cultura da virtualidade real" (CASTELLS, 2004), pois foram os saberes e experiências dos diversos participantes (conhecimento tácito e explícito) que fizeram evoluir o debate de encontro ao objetivo comum da investigação: busca de novos olhares conceituais, construção de conhecimento sobre o coempreender, conjugando os eixos das TIC e Empreendedorismo. O processo de reflexão em torno da fala de cada participante foi revelador desta busca de novos olhares. Foram destacadas algumas competências do empreendedor em rede, tais como: cooperação, colaboração, acrescentar valor, ser ativo, atrever-se, partilhar, concretizar ideias, pensar e agir com o outro, somar, sonho em ação, concretizar ideias, desafiar, buscar algo, criar, inovar, praticidade, dialogicidade, coaprender, partilhar projetos, vincular a teoria e a prática, criar oportunidade na sociedade. Utilizando a técnica da nuvem de palavras, que amplia as palavras em função da frequência, destacam-se: empreendedor, cooperação, trabalho, jovens, ideia, educação, projeto, rede, colaboração, sonho, grupo, escola, digitais, TIC e comunidade, conforme se visualiza na nuvem resultante da triangulação dos dados do Fórum e Webconferência (Figura 4).
Figura 4 - Nuvem de palavras sobre o Coempreender

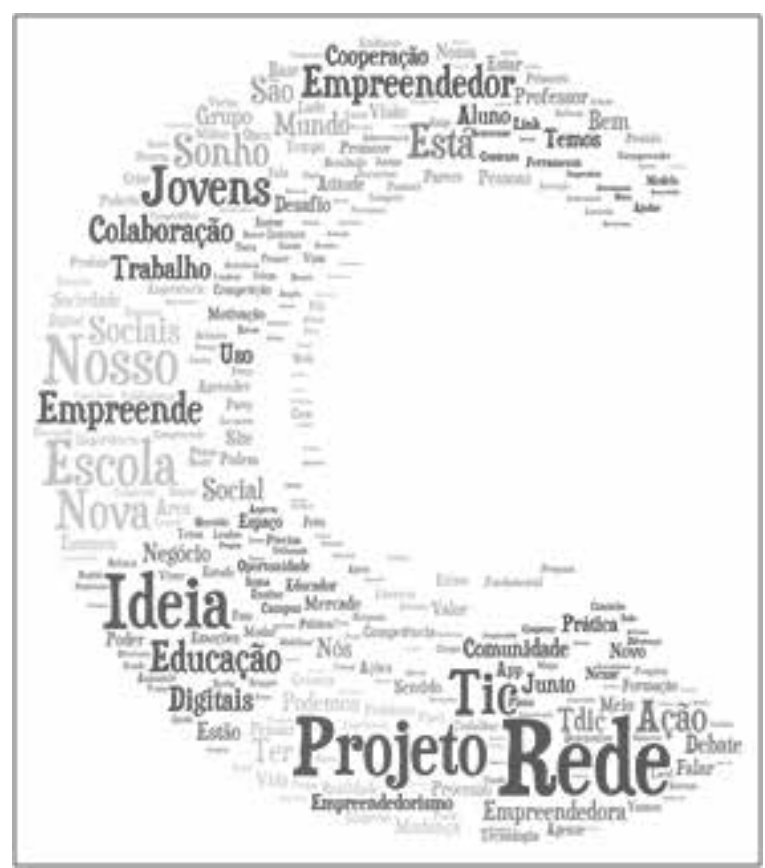

Fonte: Elaborado pelos autores deste artigo.

A rede ubíqua foi a grande responsável pela elaboração do entendimento sobre o Coempreender, pois o processo de partilha efetuado no fórum WeSPOT e na Webconferência promoveu uma ressignificação dos conceitos, para que pudéssemos perceber como a abordagem metodológica 
dialoga com autores de diferentes áreas do empreendedorismo e como uma prática de educação para o empreendedorismo pode ser instituída. A troca de experiências, discussões e partilhas deram uma nova dimensão à investigação em curso, pela valorização da coinvestigação com as pessoas no espaço online aberto.

\section{Considerações Finais}

Os resultados mostram que as tecnologias e interfaces das tecnologias ubíquas revelaram-se à altura de uma comunicação interpessoal e grupal de qualidade, pois permitiram a presença da imagem, da fala, da escrita dos participantes e ainda a partilha de outro material de natureza hipertextual, favorecendo a construção do conhecimento através de um processo comunicacional interativo entre todos os participantes (coinvestigação). Estamos já perante aplicativos da designada geração Web 4.0 (web ubíqua), que permitem antever a revolução que se aproxima para os tempos próximos na Educação e Investigação a Distância.

A rede de comunicação ubíqua foi a grande responsável pela dinamização dessa comunidade de investigação, por favorecer a integração e o sentimento de pertença entre os participantes, as trocas, discussões temáticas e a elaboração conceitual em torno da compreensão do Coempreender. A ampliação dos conceitos sobre as TIC e a educação empreendedora, efetuada tanto no Fórum como na Webconferência, permitiu a construção do conhecimento sobre o coempreender, através de uma frutuosa interação entre os conhecimentos tácitos e explícitos, mobilizando o saber de cada sujeito, em nível individual, até atingir o nível coletivo pela reflexão efetuada no grupo, em rede. Em ambos os ambientes foi possível repensar o que pode acontecer no contexto social e comunicacional da cibercultura.

O processo de comunicação ubíqua, a pedagogia da participação e a mediação colaborativa promoveram um novo olhar sobre as possibilidades de desenvolver práticas de investigação online. Com este processo reflexivo foi possível aprofundarmos a análise e sistematizar as ideias sobre o conceito do Coempreender, com base no material produzido na comunidade de investigação, pelo engajamento e envolvimento dos coinvestigadores. Ou seja, os processos do Coempreender também se constituíram com a construção e distribuição do conhecimento na Rede.

\section{REFERÊNCIAS}

ABREU, Nelsio Rodrigues; BALDANZA, Renata Francisco; GONDIM, Sônia. Os grupos focais on-line: das reflexões conceituais à aplicação em ambiente virtual. In: Journal of Information Systems and Technology Management, v. 6, n. 1, p. 05-24, 2009. Disponível em: $<$ http://www.scielo.br/scielo.php?script=sci_arttext\&pid=S1807$-17752009000100002 \& \operatorname{lng}=$ pt\&nrm=iso $>$. Acesso em: 18 abr. 2014.

BARDIN, Laurence. Análise de conteúdo. Lisboa: Edições 70, 2014.

BERNERS-LEE, Tim. The worl wide web: past, present and future. 1996. Disponível em: <http://www.w3.org/ People/Berners-Lee/1996/ppf.html>. Acesso em: 10 jul. 2012.

The future of the world wide web. 2007. Disponível em: $<$ http://dig.csail.mit.edu/2007/03/01-ushouse-future-of-the-web>. Acesso em: 10 jul. 2012.

CASTELLS, Manuel. A era da informação: economia, sociedade e cultura. Vol. I - A sociedade em rede. Lisboa: Fundação Calouste Gulbenkian, 2002. 2004.

. A galáxia internet. Reflexões sobre internet, negócios e sociedade. Lisboa: Fundação Calouste Gulbenkian,

DEPONTI, Cidonea Machado. Teoria do Ator- Rede (ANT): reflexões teóricas. In: ENCONTRO NACIONAL DA ANPPAS, 4, Brasília, DF, 2008. Anais... Brasília, DF: ANPPAS, 2008. Disponível em: <http://www.anppas.org.br/ encontro4/cd/ARQUIVOS/GT15-73-1820080418104132.pdf>. Acesso em: 20 set. 2013.

FAYOLLE, Alan (Ed.). Handbook of research in entrepreneurhip education. vol. 2. Contextual perspectives. Cheltenham: Edward Elgar, 2007. 
FILLION, Louis; DOLABELA, Fernando. Tke making of a revolution in Brazil: the introduction of entrepreneurrial pedagogy in the early stages of education. In: FAYOLLE, Alan (Ed.). Handbook of research in entrepreneurhip education. vol. 2. Contextual perspectives. Cheltenham: Edward Elgar, 2007. p. 13-39.

FOX, David. El proceso de investigación en educación. Pamplona: Universidade de Navarra, 1981.

GALEFFI, Dante, MODESTO, Maria Aparecida, SOUZA, Cláudio Reynaldo (Org.). Epistemologia, construção e difusao do conhecimento. Perspectivas em Ação. Salvador: EDUNEB, 2011

GARRISON, D. R. Three generation of technological innovations in distance education. Distance Education, v. 6, n. 2, p. 235-241, 1985.

GIBSON, William. Neuromante. Lisboa: Gradiva, 2004.

GOMES, Maria João. Gerações de inovação tecnológica no ensino a distância. Revista Portuguesa de Educação, v. 16, n. 1, p. 137-156, 2003.

Na senda da inovação tecnológica na educação a distância. Revista Portuguesa de Pedagogia, Coimbra, v. 42, n. 2, p. 181-202, 2008. Disponível em: <http://hdl.handle.net/1822/8073>. Acesso em: 20 jun. 2012.

HALMANN, Adriane; PRETTO, Nelson. Bordas de nuvens: episteme emergente na produção e difusão do conhecimento na web 2.0. In: GALEFFI, Dante, MODESTO, Maria Aparecida, SOUZA, Cláudio Reynaldo (Org.). Epistemologia, construção e difusão do conhecimento. Perspectivas em Ação. Salvador: EDUNEB, 2011. p. 219-248.

KEEGAN, Desmond. The future of learning: from eLearning to mLearning. 2002. Disponível em: <http://learning. ericsson.net/mlearning2/project_one/book.html>. Acesso em: 20 jun. 2008.

KURATKO, Donald. Entrepreneuship: theory, process, practice. South Wester: Cengage Learning, 2013.

KURZWEIL, Ray. The singularity is near: when humans transcend biology. New York: Viking Penguin, 2005.

LATOUR, Bruno. Ciência em ação: como seguir cientistas e engenheiros sociedade afora. São Paulo: UNESP, 2000.

LAW, John. Notes on the theory of the Actor-Network: ordering, strategy and heterogeneity. Systems Practice, v. 5 p. 379-393, 1992. Disponível em:<http://link.springer.com/article/10.1007\%2FBF01059830>. Acesso em: 20 set. 2013.

LÉVY, Pierre. A inteligência coletiva: por uma antropologia do ciberespaço. São Paulo: Loyola, 1998.

Cibercultura. Lisboa: Instituto Piaget, 2000.

LOPES, Rose Mary (Org.). Educação empreendedora: conceitos, modelos e práticas. São Paulo: Sebrae, 2010.

MANYKA, James. et. al. Disruptives technologies: advances that will transform life, business, and the global economy. McKinsey Global Institute. Full report, 2013. Disponível em: $<$ http://www.mckinsey.com/insights/business_technology/disruptive_technologie>. Acesso em: 20 mar. 2014.

MOORE, Michael; KEARSLEY, Greg. Educação a distância. Uma visão integrada. São Paulo: Thompson Learning, 2007.

NEGROPONTE, Nicholas. Being digital. New York: Alfred Knopf, 1995.

OKADA, Alexandra. Competências chave para coaprednizagem na era digital. Fundamentos, métodos e aplicações. Santo Tirso: Whitebooks, 2014.

O'REILLY, Tim. What is Web 2.0 - Design patterns and business models for the next generation of software. 2005. Disponível em: <http://oreilly.com/web2/archive/what-is-web-20.html>. Acesso em: 20 jul. 2012.

SAMPAIO, Renelson; SILVA, Rogério. Compartilhando saberes. In: SAMPAIO, Renelson; SOUZA, Claudio; SILVA, Rogério (Org.). Construção do conhecimento em organizações na perspectiva das Redes Sociais. Salvador: EDUNEB. 2013. p. 27-50.

SAMPAIO, Renelson; SOUZA, Claudio; SILVA, Rogério (Org.). Construção do conhecimento em organizações na perspectiva das Redes Sociais. Salvador: EDUNEB. 2013.

SANTAELLA, Lucia. Comunicação ubíqua. Repercussões na cultura e na educação. São Paulo: Paulus, 2013.

SANTOS, Edméa. Pesquisa-formação na cibercultura. Santos Tirso: Whitebooks, 2014.

SARKAR, Soumodip. Empreendedorismo e inovação. Lisboa: Escolar, 2014. 
SELBER, Stuart. Multiliteracies for a digital age. Carbondale: Southern Illinois University Press, 2004.

SENGES, Max; BROWN; John Seely; RHEINGOLD, Howard. Entrepreneurial learning in the networked age. How new learning environments foster entrepreneurship and innovation. Paradigms 1, p. 125-140, Dec. 2008. Disponível em: <http://www.gencat.cat/diue/doc/doc_52863486_3.pdf>. Acesso em: 10 mar. 2014.

SILVA, Bento. Tecnologias, ecologias da comunicação e contextos educacionais. In: MARTINS, Moisés; PINTO, Manuel (Org.). Comunicação e cidadania - Actas $5^{\circ}$ Congresso da Associação Portuguesa de Ciências da Comunicação. Braga: Centro de Estudos de Comunicação e Sociedade (Universidade do Minho), 2008. p. 1908-1920.

Cenários educativos de inovação na sociedade digital: com as tecnologias o que pode mudar na escola? In: FERREIRA, Ana Cristina (Org.). Nas pegadas das reformas educativas: Conferências do I Colóquio cabo-verdiano realizado no Departamento de Ciências Sociais e Humanas da Universidade de Cabo Verde. Praia: Universidade de Cabo Verde, 2014. p. 38-55.

SILVA, Bento; CONCEIÇÃO, Silvia. Desafios do B-learning em tempos da cibercultura. In: In: ALMEIDA, Maria Elizabeth; DIAS, Paulo; SILVA, Bento. Cenários de inovação para a educação na sociedade digital. São Paulo: Loyola, 2013. p. 137-161.

SILVA, Bento; FALAVIGNA, Gladis. Aprendizagem ubíqua na modalidade b-learning: estudo de caso do Mestrado de Tecnologia Educativa da UMinho. In: COLOQQUIO LUSO-BRASILEIRO SOBRE QUESTÕES CURRICULARES - "Currículo na contemporaneidade: internacionalização e contextos locais", 7., 2014, Braga, Portugal. Anais... Braga: Universidade do Minho, 2014.

SILVA, Bento; FERREIRA, Maria Conceição. Interacção(ões) Online e categorias de análise sobre interacções: um diálogo em construção. In: SILVA, Bento. et. al (Org.). Actas do X Congresso Internacional Galego-Português de Psicopedagogia. Braga: Universidade do Minho, 2009. p. 5780-5794.

SILVA, Bento; PEREIRA, Maria da Graça. Reflexões sobre dinâmicas e conteúdos da cibercultura numa comunidade de prática educacional. In: SILVA, Marco (Org.). Formação de professores para a docência online. São Paulo: Loyola, 2012. p. 29-51.

SILVA, Marco (Org.). Educação online. Teorias, práticas, legislação e formação cooperativa. São Paulo: Loyola, 2003.

Formação de professores para a docência online. In: SILVA, Bento. et. al. (Org.). Actas do X Congresso Internacional GalegoPortuguês de Psicopedagogia. Braga: Universidade do Minho, 2009. p. 25-40.

SILVA, Maria Graça. Mobilidade e construção do currículo na cultura digital. In: ALMEIDA, Maria Elizabeth; DIAS, Paulo; SILVA, Bento. Cenários de inovação para a educação na sociedade digital. São Paulo: Editora Loyola, 2013. p.123-135.

SOUZA, Karine. Tecnologias de informação e comunicação \& empreendedorismo: os novos paradigmas e aprendizagens de jovens empreendedores e as suas inovações tecnológicas. 2014. 659 f. Tese (Doutorado em Ciências da Educação) - Universidade do Minho, Braga, Portugal, 2014.

SOUZA, Maria Carolina; BURNHAM, Teresinha Froes. Produção e compartilhamento do conhecimento em cursos a distância. In: GALEFFI, Dante, MODESTO, Maria Aparecida, SOUZA, Cláudio Reynaldo (Org.). Epistemologia, construção e difusão do conhecimento. Perspectivas em Ação. Salvador: EDUNEB, 2011. p. 248-277.

SPIVACK, Nova. Making sense of the semantic web. 2007. Disponível em: <http://novaspivack.typepad.com/ nova_spivacks_weblog/2007/11/making-sense-of.html>. Acesso em: 13 jul. 2012.

UNIVERSIDADE DO MINHO. Visita virtual. Citânia de Briteiros. Casa do Conselho. Braga, Portugal, 2015. Disponível em: <http://citania.csarmento.uminho.pt>. Acesso em:15 maio 2014.

WATZLAWICK, Paul; BEAVIN, Janet; JACKSON, Don. Pragmática da comunicação humana. São Paulo: Cultrix, 1973.

WENGER, Etienne; MCDERMOTT, Richard; SNYDER, William. Cultivating communities of practice: a guide to managing knowledge. Boston: Harvard Business Scholl Press, 2002.

Recebido em: 30.06 .2015

Aprovado em: 04.08.2015 